\title{
Change detection and building spatial geodatabase for Iraqi marshes
}

\author{
Oday Jasim ${ }^{1, *}$, Noor Hamed $^{1}$, and Tamarra Abdulgabar ${ }^{2}$ \\ ${ }^{1}$ Building and Construction Department, University of Technology, Baghdad , Iraq \\ ${ }^{2}$ Ministry of Labour and Social Affairs, Baghdad, Iraq
}

\begin{abstract}
The Iraqi Marshlands has natural and economic potential through its environment rich in various forms of lives. This region has suffered numerous setbacks due to human and natural factors, especially in the last two decades of the last century, which led to significant environmental degradation. The purpose of this paper is to prepare spatial data for the area of the marshes in Iraq as a base (Hour-al Hoveizah and central marshes and Hammar). Also, the other aim is to produce a digital geodatabase for the marshes for the years 1973, 1986, 1999, 2006 and 2016 by using ArcGIS. The process of building geodatabase has been through done in three stages: the first stage is including data collection. The second stage will be by merging the satellite images covering the Iraqi marshes and add to images in order to get the image mosaic process. Also, a georeferencing of satellite images is to be done with all the traditional maps of the same area of the marsh. Finally, complete the full geodatabase for the area of interest by using ArcGIS as the in Cartography Design. The results of this research would be a geodatabase for the Iraqi marshes.
\end{abstract}

\section{Introduction}

The Iraqi marshes are considered one of the oldest areas with population stability on their lands. The number of population in the marshes area increased during the years of 1977-1997. The population growth rate was $1.9 \%$ between the censuses from 1977 to 1987. The population rate decreased to $0.5 \%$ between1987 to 1997 . While in the period between $1997-2009$ the population growth rate has dropped to $-0.6 \%$. The decline in the rate of population growth has occurred due to several reasons. The main reason was the migration of people from the marshes to the province and district centres or other provinces because of the drying and military events and the lack of employment opportunities. The marshes suffered from neglect through poor infrastructure and drying due to no program or development plans. The relationship between man and the environment of social and economic could not be represented, analysed or studied without reference to spatial location. The environment and social and economic activities are closely linked and it is not possible to understand and see the changes taking place or develop without reference to the spatial dimension. GIS provides enormous possibilities to deal with the data within the system of spatial databases. The success of any database depends on the quality and efficiency of the spatial data that form the backbone of any system. Database-building phase needs to be accurate in the collection and incorporation of information in order to get good analysis result. Data is available in multiple formats including spatial information. The spatial information includes maps, aerial photographs or satellite. Also, statistical data has attributes not related to the geographical location. There is sophisticated software that connects between the spatial and statistical data and gives users the possibility of collection, storage, and analysis of data and this so-called term is geoinformation. For the purpose to improve the status of these areas and to prepare or update basic designs to preserve the natural and social environment, the database has to be set up for the Iraqi marshes during different periods depending on the satellite imagery and maps by using geoinformation for its ability to store and update spatial and non-spatial data and find what the relationships between spatial and non-spatial data are.

\section{Literature review}

There are several studies have been published that might be more important due to the aim of this research, such as:

- Aseel Abbas Salman, (2006) has showed selected visible bands in the digital visual interpretation process is considered an optimum technique to observe the soil types using remote sensing techniques. Also, she has been constructed a geographical database and information about layers of soil of the overall studied area (ALhammar marshes) digitally to represent the geotechnical soil characteristics in associated

\footnotetext{
* Corresponding author: 40004@uotechnology.edu.iq
} 
files, and produced digital soil map by using GIS techniques depending on remote sensing data. [2]

- Noor Mahdi alaq, (2011), has assessed the effect of climate factors on marshland of southern Iraq by using remote sensing techniques. She has studied the influence of seasonal climatic factors on floor coverings for the marshes and the possibility of a connection between the marsh area and evaporation using remote sensing techniques and satellite images classified. [3]

- Hussein Kareem Alsaaidi, (2014) has conducted a hydrological study for the marshland of the Shweja, Saadiya, and Dalmaj. He has presented the analysis of physical and chemical properties of marshes to identify causes of decreased amounts of water throughout the drought period and developed proposals for developing the ecological realities of the region.

\section{Description of study area}

The Iraqi marshes located in the central region and the south of the Tigris and Euphrates rivers, along three governorates (Basra, Masan, and Di kar) as shown in figure.1. The most important marshlands are (Alhammar, the central marshes and Hovaiza). The Iraqi marshes have several advantages including biodiversity of a variety of wildlife, animal, plant, numerous kinds of fish and millions of birds [5].

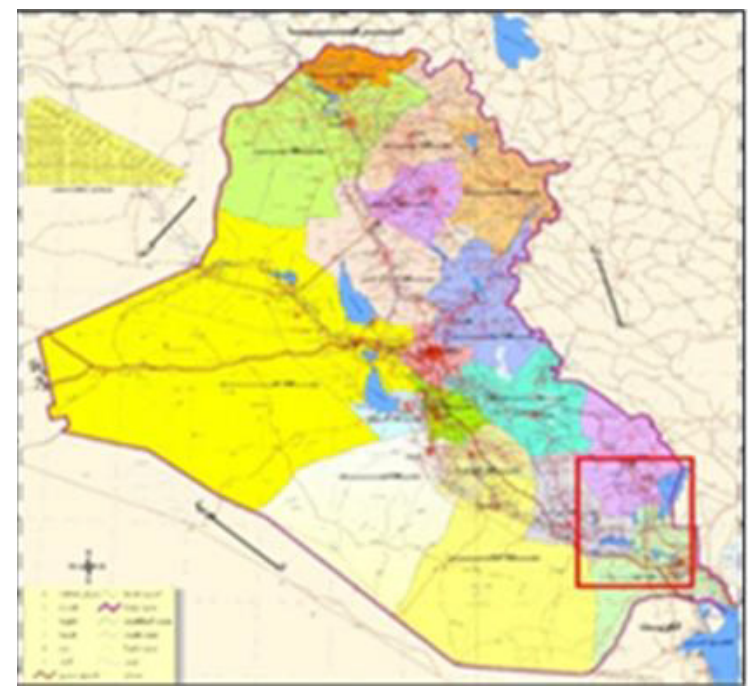

Fig. 1. Study area in south Iraq.

\section{Methodology of work}

Requiring of an appropriate spatial data for Iraqi marshlands was represented by collecting four old marsh's maps and downloading five satellite images for study area. The marsh's map sheets were of scale $1 / 250000$ for years $1973,1986,1999$, and 2006. The five satellites images include two MSS collected in
1973, 1988, two TM collected in 1999, 2006, and one sentinel image collected in 2016. Additional data was collected from government offices. These data include name and area of the marshes, and the factors affecting the low or high water levels. Thus these factors impact the increase or decrease of tracked marshes.

Processing and interpretation of images are basic steps for development of geodatabase and digital maps for Iraqi marshes by using Arc GIS as in the cartography design. The obtained maps are analysed to detect changes in marsh's areas.

\subsection{Image processing}

Mosaicking and matching for all scenes to produce satellite image of Area of Interest (AOI) marsh for each of interest year. All satellite images were geo referenced, which is the simplest way to link an image to a map projection system by geometric transformation. A transformation is a function that relates the coordinates of two systems. Once such a transformation has been determined, the map coordinates for each image pixel can be calculated. The resulting image is called a georeferenced image. [4]

\subsection{Building geodatabase}

Layers are determined and established to represent features. These features represent various items, such as shallow and deep marshes, road network, administration boundary, villages, and rivers. Also, attribute data has been designed for each feature. These layers will be used in producing the marsh's map with the desired scale and year.

\subsection{Topology process}

If a geospatial vector dataset is derived from a reference dataset either by digitizing or copying geometries, both datasets have a topological relationship. Topology represents a set of rules that prevent interference and overlap of a single or a number of layers. This overlap causes a repeat of spaces. To get high spatial accuracy, it is necessary to hold topology process after screen digitizing process, or topology is the numerical description of the relationships between geographic features, as encoded by adjacency, linkage, inclusion, or proximity [5].

\subsection{Layout process}

Outputs are the final result and can be either in the form of maps, schemas or reports. The scale of the map is an essential factor in this process. Determining of the scale of $1 / 50000$ and adding other maps elements are applied to produce a map of Iraqi marshes for years 1973, 1986, 1999, 2006, and 2016. Brief Technical Methodology for building 
geodatabase, production map for Iraqi marshes with scale $1 / 50000$, and detecting changes in their area by using GIS and remote sensing techniques are presented in steps. The main steps for that methodology are shown in Table 1.

Table 1. Production and updating map with generalization

\begin{tabular}{|c|c|}
\hline Item & Description \\
\hline 1 & $\begin{array}{c}\text { Collect, prepare and enter spatial data for the } \\
\text { Marshlands area (satellite images and traditional } \\
\text { maps) }\end{array}$ \\
\hline 2 & $\begin{array}{c}\text { Combine the satellite images covering the study } \\
\text { area with (7) images and making them as unified } \\
\text { image in the process of mosaics }\end{array}$ \\
\hline 3 & Geo reference process for raster images. \\
\hline 4 & $\begin{array}{c}\text { Create spatial geo data base through Arc catalog } \\
\text { window }\end{array}$ \\
\hline 5 & $\begin{array}{c}\text { Correct interpretation of the imagery or map based } \\
\text { on the map legend }\end{array}$ \\
\hline 6 & $\begin{array}{c}\text { Start digitizing of the features from satellite images } \\
\text { and traditional maps through the Arc map window } \\
\text { with activation of SNAPPIN }\end{array}$ \\
\hline 7 & $\begin{array}{c}\text { Conversion of the digitized features into the geo } \\
\text { data base GIS layers }\end{array}$ \\
\hline 8 & $\begin{array}{c}\text { Carry out topology process and fill attribute data } \\
\text { Production of digital maps of the Iraqi Marshlands } \\
\text { for the years (1973, 1986, 1999, 2006, 2016) with } \\
\text { scale1/ 500000 }\end{array}$ \\
\hline
\end{tabular}

And for all these items descriptions the practical works with the geomatics software such as ERDAS, ARC GIS 9.3 occurs as shown in figures 2, 3, 4, 5, 6, and 7.

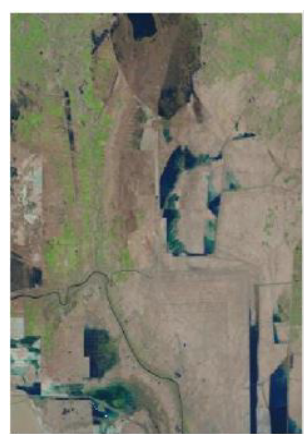

(a)

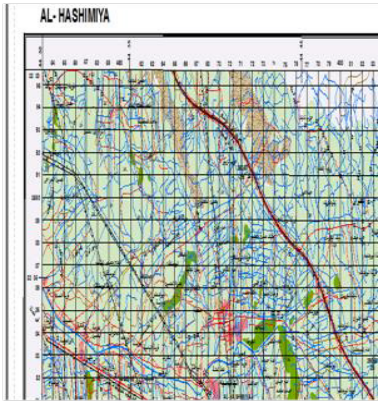

(b)
Fig.2. The collected data: (a) satellite image, (b) traditional map.

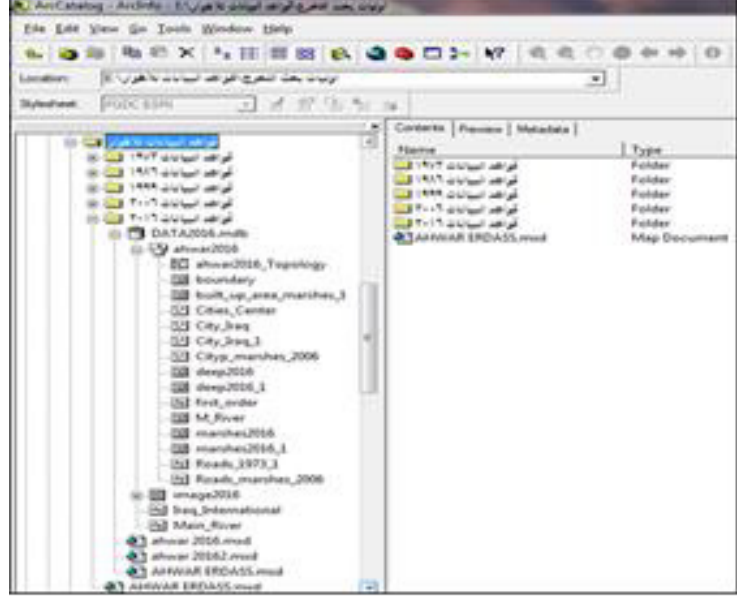

Fig.3. Shows creating geodatabase.

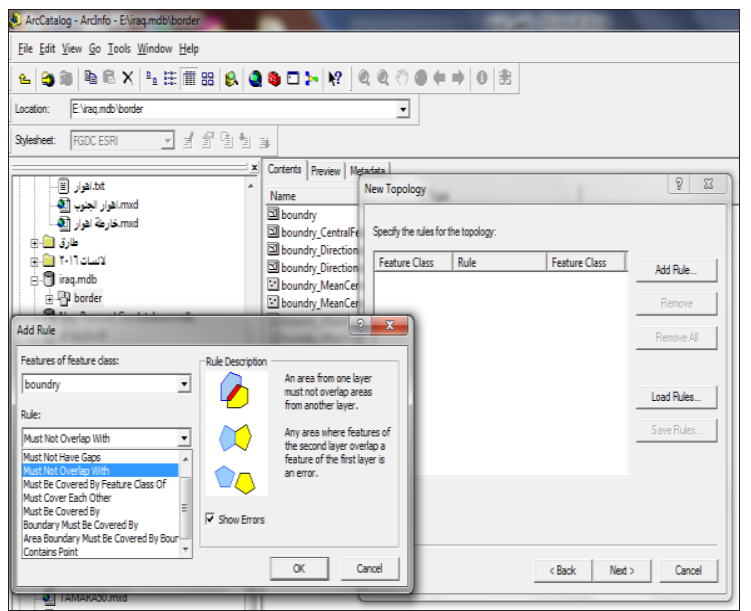

Fig.4 .Shows digitizing of features.

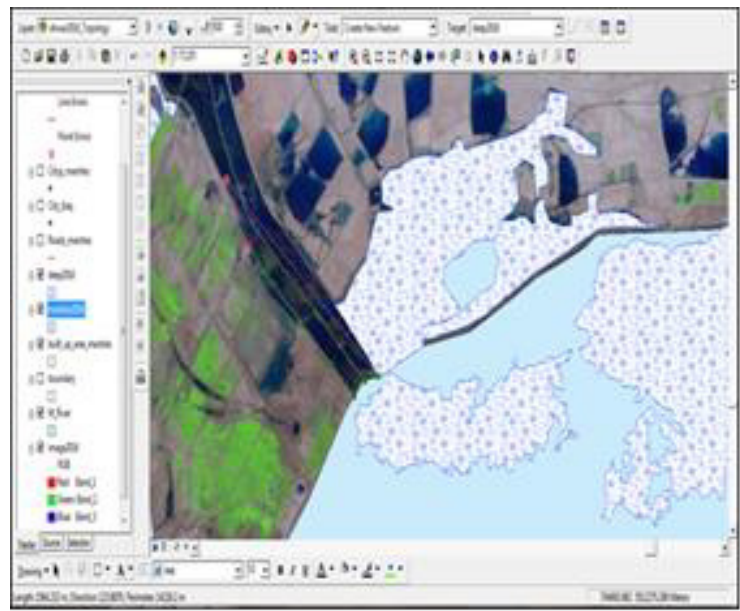

Fig.5.Shows the topology. 


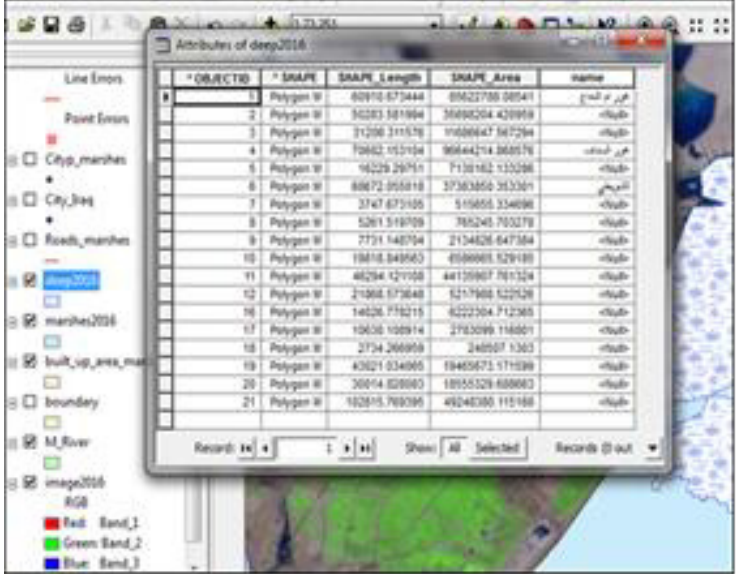

Fig. 6. Shows attributes data of Iraqi marshes.

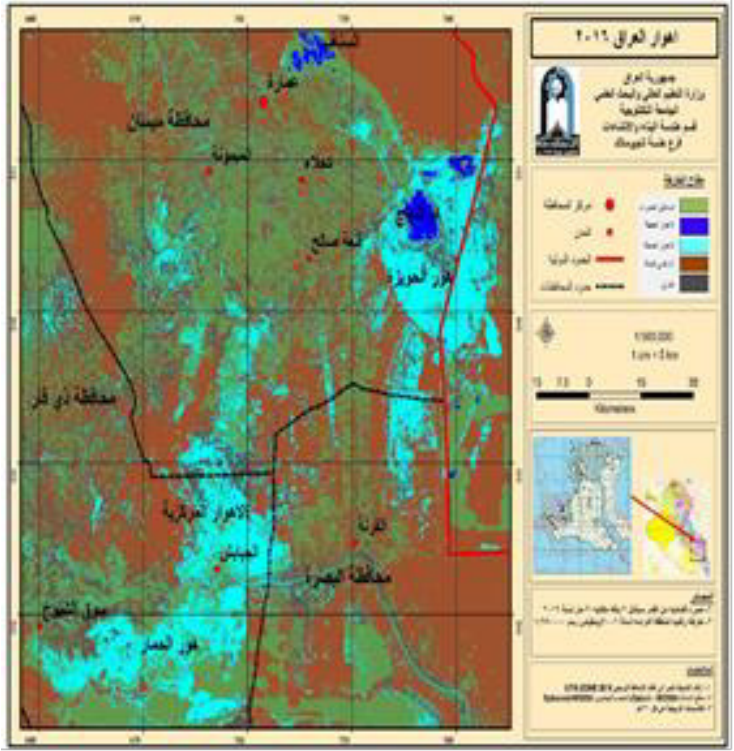

Fig.7.Shows Iraqi marshes map for year 2016.

\section{Summary and Conclusions}

The produced maps and calculated area for the Iraqi marshes during different decades by using Arc GIS software have shown the presence of the area of these marshes, which reached at their highest level in 1973 of about $892.383 \mathrm{~km}^{2}$ and the swamp (flood area) of about $9076 \mathrm{~km}^{2}$. Since 1986, and during the Iran-Iraq war, these marshes area was reduced to about 1150 $\mathrm{km}^{2}$ and the swamp area was reduced to $6442 \mathrm{~km}^{2}$. In 1999 marshes areas reached to the lowest levels due to the continuous drying processes during the drying period which lasted more than a decade where many of the marshes in those areas disappeared, and the marsh areas reduced to $419 \mathrm{~km}^{2}$ and swamp marshes reduced to $769 \mathrm{~km}^{2}$.

In 2006, after attempts to revitalize the marshes, these marshes have begun increasing these areas from what it was at the end of the nineties. The deep marsh areas have amounted to about $782 \mathrm{~km}^{2}$ while shallow marshes reached $3333 \mathrm{~km}^{2}$. From 2016 until now, the study area is about $926 \mathrm{~km}^{2}$ while swamp marshes are about $2466 \mathrm{~km}^{2}$.

Remote sensing data is primary source, extensively used for change detection in recent decades. The main information on land use /land cover in the form of maps and statistical data is very vital for spatial planning. In this research, remote sensing and geographic information system (GIS) were used in order to study land use /land cover changes for the period of marshes in the history in Iraq. The use of remotely sensed data (satellite and aerial) to detect changes in land use as well as precise and accurate analysis using GIS is widely preferred over other conventional survey techniques because the method is very efficient for assessing the change or degrading trends of a region.

Finally, planning and decision making processes are dependent on geomatics, especially with engineering works. Geomatics must be recognized for the public to communicate with world technology.

\section{References}

1. A. Salman, (Master thesis), (2006)

2. N..Alaq, (Master thesis), (2011)

3. H. Alsaaidi, (Doctoral dissertation), (2014)

4. Wim H. Bakker, Lucas L. F. Janssen, Principles of Remote Sensing An introductory textbook (ITC Educational Textbook Series 2001)

5. Shahab F. GIS basics (Published by New Age International Ltd, New Delhi, 2008) 